\title{
Haloalkane induced hepatic insult in murine model: amelioration by Oleander through antioxidant and anti-inflammatory activities, an in vitro and in vivo study
}

Priyankar Dey ${ }^{1}$, Somit Dutta ${ }^{1}$, Anashuya Biswas-Raha ${ }^{2}$, Mousumi Poddar Sarkar ${ }^{2}$ and Tapas Kumar Chaudhuri ${ }^{\text {* }^{*}}$

\begin{abstract}
Background: Nerium oleander L. (syn. Nerium indicum Mill, Nerium odorum Aiton) belongs to the family Apocynaceae. It is used for its anti-inflammatory, anti-diabetic, anti-cancer and hepatoprotective activities in traditional medicine. Previous pharmacognostic studies suggested that $70 \%$ hydro-methanolic extracts of oleander possess potent free radical scavenging and anti-inflammatory activities, both of which are helpful against hepatotoxicity.

Methods: Hydro-methanolic extracts of oleander stem and root were evaluated for their hepatoprotective activities in acute $\mathrm{CCl}_{4}$ intoxicated mouse through in vitro and in vivo studies. Silymarin was used as positive reference. Antioxidant enzymes, pro-inflammatory markers and liver enzymatic and biochemical parameters were studied. The extracts were further chemically characterized using Fourier Transform Infrared (FTIR) spectroscopy and Gas chromatography-mass spectrometry (GC-MS).

Results: $\mathrm{CCl}_{4}$ toxicity caused fatty liver formation by increase of relative liver weight ( $\left.32.53 \mathrm{~g}\right)$ compared to control group (16.08 g). The elevated liver enzymatic and biochemical parameters due to $\mathrm{CCl}_{4}$ toxicity were considerably normalized by the extracts treatment under both in vivo and in vitro models. Oleander stem (NOSE) and root (NORE) extracts increased the reduced hepatic catalase activity 27.37 and $25.25 \%$, whereas peroxidase activity was increased 18.19 and $22.78 \%$, respectively. The extent of lipid peroxidation was significantly $(p<0.01)$ lowered $20.76 \%$ (NOSE) and $21.12 \%$ (NORE) compared to $\mathrm{CCl}_{4}$ group. The levels of pro-inflammatory tumor necrosis factor-a (TNF-a) was lowered $71.33 \%$ (NOSE) and $61.60 \%$ (NORE). Histopathological study demonstrated substantial reduction of hepatocellular necrosis, fatty infiltration, sinusoidal dilation, bile duct proliferation, vascular congestion, leukocyte infiltration in the silymarin and extract treated groups. Furthermore, various bioactive compounds were identified in the extracts such as apocynin, tocopherol, squalene, vanillin, isoeugenol, amyrin, lupeol etc.

Conclusion: The present study provided convincing evidence that oleander extracts possess potent hepatoprotective capacity which was primarily governed by its antioxidant and anti-inflammatory activities. The collegial bioactivities of the phytochemicals may be accredited behind the hepatoprotective activity of oleander.
\end{abstract}

Keywords: Hepatoprotective, Inflammation, Liver, Nerium, Oxidative stress, Xenobiotic

\footnotetext{
*Correspondence: dr_tkc_nbu@rediffmail.com; tapas.chaudhuri@gmail.com

${ }^{1}$ Cellular Immunology Laboratory, Department of Zoology, Life Science

Building, University of North Bengal, PO: Raja Rammohunpur, Siliguri 734013,

West Bengal, India

Full list of author information is available at the end of the article
} 


\section{Background}

The liver is the largest organ of our body, contributing about $2 \%$ of the total body weight. The liver is associated with most of the metabolic and physiological process including growth, immunity, nutrition, energy metabolism and reproduction [1]. Production of different coagulation factors, antithrombin, thrombopoietin, angiotensinogen, insulin-like growth factor 1, albumin, catabolism of bilirubin and various hormones takes place in the hepatic system. Liver performs central role in the biotransformation and metabolism of xenobiotic compounds, which in some case results in liver damage [2]. Though the liver possesses tremendous regenerative capacity, but very often subclinical live injury occurs due to toxic chemicals and their metabolic intermediates. Around the globe, drug induced hepatotoxicity has emerged as a serious medical concern where $10 \%$ cases of acute liver failures are associated with idiosyncratic hepatotoxicity [3]. Drug induced hepatotoxicity has now appeared as the leading cause behind acute liver failure among the US patients [4]. The liver is one of the decisive organs of the body and therefore, requires safeguard from harmful chemicals.

Persistent exposure to xenobiotics, especially synthetic drugs and environmental chemicals cause serious liver damage due to its portal location in the circulation and central role in detoxification $[5,6]$. Most xenobiotics are lipophilic in nature and thus, are poorly excreted by the kidney. The liver performs a critical role in biotransformation of such xenobiotics to more polar form in order to facilitate their excretion [7]. Halogenated alkanes are organic xenobiotics which holds the potentiality to cause severe liver injury $[2,6] . \mathrm{CCl}_{4}$ is a model haloalkane which is extensively used to study the pathophysiological implications of xenobiotic metabolism and hepatoprotective potentialities of natural compounds [8]. Xenobiotic mediated liver damage like $\mathrm{CCl}_{4}$ toxicity, is primarily governed by free-radical mediated tissue injury and inflammatory damages. $\mathrm{CCl}_{4}$ cause hepatocellular ionic imbalance, oxidative stress, translational inhibition, $\mathrm{Ca}^{2+}$ shift, mitochondrial respiratory chain blockage and impairment of $\beta$-oxidation $[9,10]$. Histopathological signs of $\mathrm{CCl}_{4}$ toxicity includes zonal haemorrhagic necrosis, fatty infiltration, sinusoidal dilation, calcification, vascular congestion, bile duct proliferation and leukocyte infiltration [8].

Previously, we have demonstrated that the $70 \%$ hydro-methanolic extracts of oleander possess potent antioxidant capacity [11]. The extracts also demonstrated free radical scavenging activities against various reactive species associated with hepatotoxicity such as hydroxyl $\left(\mathrm{OH}^{\bullet}\right)$, superoxide $\left(\mathrm{O}_{2}{ }^{\bullet-}\right)$, peroxynitrite $\left(\mathrm{ONOO}^{-}\right)$, singlet oxygen $\left({ }^{1} \mathrm{O}_{2}\right)$, hydrogen peroxide $\left(\mathrm{H}_{2} \mathrm{O}_{2}\right)$ and nitric oxide (NO), in addition to potent iron $\left(\mathrm{Fe}^{2+}\right)$ chelation activities, overload of which may lead to haemochromatic liver [12].
It is interesting to note that, a recent in vivo preliminary study demonstrated that $N$. indicum leaf extract ameliorates haemochromatic conditions in mouse [13]. Moreover, another recent study showed that $N$. indicum leaf extract attenuates $\mathrm{CCl}_{4}$ mediated hepatotoxicity in Swiss albino mouse [14]. Simultaneously, the same $70 \%$ hydro-methanolic extract of oleander leaf possess anti-inflammatory activities by modulation of Th1/ Th2 cytokine balance, inhibition of cyclooxygenase, prostaglandin $\mathrm{E}_{2}\left(\mathrm{PGE}_{2}\right)$ and nitric oxide levels in mitogen induced splenic lymphocytes $[15,16]$. Moreover, diverse pharmacognostic activities such as antidiabetic, anti-microbial, antinociceptive, neuroprotective, anti-ulcer, anti-cancer etc. of oleander extracts and oleander derived bioactive components has also been demonstrated previously [17].

Oleander is extensively used as herbal medicine in different parts of the world [17]. The pharmacognostic studies are mostly limited to the bioactivities of its leaf extracts. However, traditional therapies suggests extensive use of oleander stem and root to cure diverse ailments [17]. Therefore, the present study was initiated to evaluate the proposed hepatoprotective potentiality of steam and root extracts of oleander against haloalkane induced hepatic injury in murine model. The study was supported by both in vitro and in vivo experiments. Further, phytochemical characterization were carried out using FTIR and GC-MS methods to reveal the bioactive constituents in the extracts and to correlate the individual bioactivities of the phytochemicals with the proposed hepatoprotective potentiality of oleander stem and root.

\section{Methods}

\section{Chemicals}

All the chemicals were procured from Sisco Research Laboratories Pvt. Ltd. (Mumbai, India) unless otherwise indicated. Silymarin was obtained from Sigma-Aldrich (USA). Fetal bovine serum (FBS), RPMI-1640, antibiotics and EZcount ${ }^{\mathrm{sin}}$ MTT (3-(4,5-dimethylthiazol-2-yl)-2,5-diphenyltetrazolium bromide) Cell Assay Kit were purchased from HiMedia Laboratories Pvt. Ltd. (Mumbai, India). Albumin, $\gamma$-glutamyl transferase (GGT), lactate dehydrogenase (LDH), alkaline phosphatase (ALP), bilirubin, protein, aspartate transaminase (AST), acid phosphatase (ACP), alanine transaminase (ALT), glucose, urea and cholesterol estimation kits were obtained from Crest Biosystems (Goa, India). TNF- $\alpha$ ELISA kit was procured from Ray Bio (Georgia, United States) and Thiobarbituric acid reactive substances (TBARS) assay kit was purchased from Cayman chemical company (USA). Milli-Q ultrapure water from the departmental central facility was used in the experiments. 


\section{Preparation of plant extract}

Stem and root samples of white flowered variety of oleander were collected from the garden of University of North Bengal $\left(26.71^{\circ} \mathrm{N}, 88.35^{\circ} \mathrm{S}\right)$, India. The plant materials were identified by senior plant taxonomist Prof. Abhaya Prasad Das of Department of Botany, University of North Bengal. The voucher specimen was stored at the herbarium of Department of Botany, University of North Bengal with an accession number of 09618.

The stem and root samples were washed properly with double distilled water to remove any dust and foreign materials. The samples were then chopped to $0.5 \mathrm{~cm}$ pieces and shade dried at laboratory temperature $\left(25{ }^{\circ} \mathrm{C}\right)$. After 20 days, $70 \%$ hydro-methanolic extract of Oleander stem and root were prepared according to the previous method [11]. A schematic representation of the extract preparation method is provided in the Additional file 1. The lyophilized extracts were stored at $-20{ }^{\circ} \mathrm{C}$ until further use. The final yield of oleander stem (NOSE) and root (NORE) extracts were 11.82 and $15.22 \%$ of dry weight (DW).

\section{Animal maintenance}

Swiss albino mice (6-8 weeks, $20-25$ g) of both sex (3 male and 3 female per group) were maintained inside cage bins (Tarson, India) with rice husk bedding in the animal house of the Department of Zoology, University of North Bengal at a constant $12 \mathrm{~h}$ photoperiod (temperature $25 \pm 2{ }^{\circ} \mathrm{C}$; humidity $55 \pm 5 \%$ ) with food and water ad libitum. All the experiments were approved by the ethical committee, University of North Bengal (No. 840/ac/04/CPCSEA) and conducted in accordance with the legislation for the protection of animals used for scientific purposes.

\section{Acute toxicity study}

OECD guidelines (test 423: Acute oral toxicity - Acute toxic class method, 2002) were followed to study the acute toxicity of the extracts [18]. Mice were divided into eight groups $(n=6)$ and fasted overnight prior to the experiment. NOSE and NORE were administered orally at 250, 500, 1000 and $2000 \mathrm{mg} / \mathrm{kg}$ body weight (bw) dose. Each groups were carefully observed at $30 \mathrm{~min}$ and then 2, 4, 8, 24 and $48 \mathrm{~h}$ for development of any clinical or toxicological symptoms such as tremors, convulsions, salivation, diarrhoea, lethargy, sleep, coma and alteration in respiratory patterns, skin colour, behaviour pattern etc.

\section{Experimental design: in vivo}

Animals were divided into 7 separate groups $(n=6)$ and following treatments were done once each day for 10 consecutive days: Control group received normal saline; $\mathrm{CCl}_{4}$ group received 1:1 (v/v) $\mathrm{CCl}_{4}$ in olive oil; Silymarin group received 1:1 (v/v) $\mathrm{CCl}_{4}$ in olive oil and $100 \mathrm{mg} / \mathrm{kg}$ bw silymarin; NOSE low group received 1:1 (v/v) $\mathrm{CCl}_{4}$ in olive oil and $50 \mathrm{mg} / \mathrm{kg}$ bw NOSE; NOSE high group received 1:1 (v/v) $\mathrm{CCl}_{4}$ in olive oil and $200 \mathrm{mg} / \mathrm{kg}$ bw NOSE; NORE low group received 1:1 (v/v) $\mathrm{CCl}_{4}$ in olive oil and $50 \mathrm{mg} / \mathrm{kg}$ bw NORE; NOSE high group received 1:1 (v/v) $\mathrm{CCl}_{4}$ in olive oil and $200 \mathrm{mg} / \mathrm{kg}$ bw NORE.

On $11^{\text {th }}$ day i.e., $24 \mathrm{~h}$ after the last treatment, under anaesthesia ( $2 \%$ ether), blood was collected from the treated animals by cardiac puncture and finally the animals were sacrificed. Blood was allowed to clot for $60 \mathrm{~min}$ at room temperature $\left(25^{\circ} \mathrm{C}\right)$ and then serum was collected by centrifuging at $1000 \mathrm{rpm}$ for $5 \mathrm{~min}$. The straw coloured serum was used to study liver marker enzymes. Liver samples were collected and washed with double distilled water to remove blood and used for antioxidant enzymatic assays. Liver tissue required for histological study were collected in Bouin's solution.

\section{Liver function test: in vivo}

Serum samples from each group were used to study ACP, albumin, globulin, glucose, ALP, bilirubin, cholesterol, LDH, GGT, AST, ALT, total protein and urea levels using commercially available kits (Crest Biosystems).

\section{Estimation of peroxidase and catalase activities}

Peroxidase activity in the liver samples were estimated by measuring the oxidation of guiacol according to a standard method [19]. Catalase activity was measured by degradation of substrate $\mathrm{H}_{2} \mathrm{O}_{2}$ by catalase in the liver tissue samples following the standard method described by Luck [20].

\section{Experimental design: in vitro}

The in vitro hepatoprotective capacity of NOSE and NORE were studied according to previously standardized methods with minor modifications [14, 21, 22]. Briefly, seven groups of primary explant culture of mice hepatocytes were prepared in RPMI-1640 medium (containing $50 \mathrm{U} / \mathrm{ml}$ penicillin, $50 \mathrm{U} / \mathrm{ml}$ streptomycin and 50 $\mathrm{U} / \mathrm{ml}$ nystatin) supplemented with $10 \% \mathrm{FBS}$. After $48 \mathrm{~h}$ of the culture, the following treatments were done: Control had no separate treatment; $\mathrm{CCl}_{4}$ group received $25 \mu \mathrm{l} / \mathrm{ml} \mathrm{CCl}_{4}$; Silymarin group received $25 \mu \mathrm{l} / \mathrm{ml} \mathrm{CCl}_{4}$ and $100 \mu \mathrm{g} / \mathrm{ml}$ silymarin; NOSE low group received $25 \mu \mathrm{l} / \mathrm{ml} \mathrm{CCl}_{4}$ and $25 \mu \mathrm{g} / \mathrm{ml}$ NOSE; NOSE high group received $25 \mu \mathrm{l} / \mathrm{ml} \mathrm{CCl}_{4}$ and $100 \mu \mathrm{g} / \mathrm{ml}$ NOSE; NORE low group received $25 \mu \mathrm{l} / \mathrm{ml} \mathrm{CCl}_{4}$ and $25 \mu \mathrm{g} / \mathrm{ml}$ NORE and NORE high group received $25 \mu \mathrm{l} / \mathrm{ml} \mathrm{CCl}_{4}$ and $100 \mu \mathrm{g} / \mathrm{ml}$ NORE.

The plates were incubated for $2 \mathrm{~h}$ and then culture supernatants were collected by centrifugation $(5000 \mathrm{rpm}$ for $10 \mathrm{~min}$ ). 


\section{Liver function test: in vitro}

Culture supernatants from each group were analysed for ACP, ALP, bilirubin, LDH, AST, ALT and total protein levels using commercially available kits (Crest Biosystems).

\section{Measurement of lipid peroxidation}

The extent of lipid peroxidation was measured in six sets using TBARS assay kit (Cayman) according to the manufacturer's instructions. In brief, $100 \mu \mathrm{l}$ serum samples of different groups were mixed with $100 \mu \mathrm{l}$ sodium dodecyl sulphate (SDS) solution. The tubes were placed on boiling water bath after addition of $4 \mathrm{ml}$ colour reagent. After $60 \mathrm{~min}$ incubation, the tubes were kept on ice for $10 \mathrm{~min}$ to stop the reaction. Then the solutions were centrifuged $(1600 \mathrm{~g})$ for $10 \mathrm{~min}$ at $4{ }^{\circ} \mathrm{C}$ and the absorbance of the supernatants were recorded at $340 \mathrm{~nm}$.

\section{Measurement of TNF- $a$}

The amount of TNF- $\alpha$ released in culture supernatants were measured using TNF- $\alpha$ ELISA kit (Ray Bio) according to the manufacturer's instructions. Absorbance was immediately measured at $450 \mathrm{~nm}$ using Bio-Rad iMark ${ }^{\text {тм }}$ microplate absorbance reader. Standard was run in parallel to the samples.

\section{Measurement of inhibition of NO}

Culture supernatants were used to determine the NO level using the Griess reagent method [23] with some modifications. Briefly, culture supernatants $(60 \mu \mathrm{l})$ from each group was mixed with $240 \mu \mathrm{l}$ of Griess reagent ( $1 \%$ sulfanilamide and $0.1 \% \mathrm{~N}$-(1-naphthyl) ethylenediamine hydrochloride in $2.5 \% \mathrm{H}_{3} \mathrm{PO}_{4}$ ) in a 96-well plate and incubated for $20 \mathrm{~min}$ at room temperature. The purple azo-dye formed, was detected at $540 \mathrm{~nm}$.

\section{Measurement of cell viability}

Hepatocyte necrosis results due to $\mathrm{CCl}_{4}$ toxicity. Therefore, MTT assay was performed to measure the protection rendered by NOSE and NORE against $\mathrm{CCl}_{4}$. mediated toxicity. Hepatocytes were cultured as described under the in vitro experimental section. The cell viability assay was performed in six sets using EZcount $^{\text {Tax }}$ MTT Cell Assay Kit (HiMedia) according to the manufacturer's instructions.

\section{Histopathological studies}

Liver samples were removed from the animals of the in vivo experiments after collection of blood and were fixed overnight in $10 \%$ buffered formalin. The samples were subjected to dehydration and then embedded in paraffin blocks. Thick sections $(4 \mu \mathrm{m})$ of the paraffin embedded livers were cut in a microtome and then dewaxed in xylene, rehydrated in a series of different grades of alcohol and then washed with distilled water for $5 \mathrm{~min}$.
Subsequently, the sections were stained with haematoxylin for $40 \mathrm{~s}$ and counterstained with eosin for $20 \mathrm{~s}$. The sections were dehydrated in graded alcohol series and washed in xylene. The slides were observed $(100 \times$ and $400 \times$ ) for signs hepatic injury using Nikon ECLIPS E200 microscope.

\section{Fourier Transform Infrared (FTIR) spectroscopy analysis} FTIR spectrophotometry was used to identify the characteristic functional groups in NOSE and NORE. Small quantity $(<10 \mathrm{mg})$ of dried extracts were taken in $\mathrm{CaF}_{2}$ vessel and placed in the sample cup of a diffuse reflectance accessory. The IR spectrum was obtained using Shimadzu 8300 FTIR spectrophotometer at ambient temperature. Background correction was made by taking IR spectrum of de-ionized water as the reference in identical condition. The sample was scanned from 400 to $4000 \mathrm{~cm}^{-1}$ for 16 times to increase the signal to noise ratio.

\section{GC-MS analysis}

NOSE and NORE were initially bi-fractionated by dissolving in dichloromethane and n-hexane separately. The mixtures were centrifuged thrice $(12,000 \mathrm{rpm})$ for $15 \mathrm{~min}$. The clear supernatant was used for GC-MS analysis using Agilent 5975C GC-MS system (Agilent Technologies, USA) attached with HP-5 ms Capillary Column (30 m $\times$ $0.25 \mathrm{~mm}$ i.d. $\times 0.25 \mu \mathrm{m}$ film thickness). The machine was equipped with inert MSD triple axis mass detector conditioned at ion trap $200{ }^{\circ} \mathrm{C}$, transfer line $280{ }^{\circ} \mathrm{C}$, electron energy $70 \mathrm{eV}$ (vacuum pressure- $2.21 \mathrm{e}-0.5$ torr) was used for analysis. Helium was used as carrier gas $(1 \mathrm{ml} / \mathrm{min})$. Sample volume was $2 \mu \mathrm{l}$ and injected in a splitless mode. The column temperature was kept at $60^{\circ} \mathrm{C}$ for $1 \mathrm{~min}$ followed by $5{ }^{\circ} \mathrm{C} / \mathrm{min}$ up to $250{ }^{\circ} \mathrm{C}$. The major and essential compounds present in samples were identified by their retention times and mass fragmentation patterns using Agilent Chem Station Integrator and the database of National Institute Standard and Technology (NIST) with a MS library version 2010 .

\section{Statistical analysis}

All data are reported as mean \pm SD of six measurements. Statistical analysis was performed and graphs were prepared using KyPlot Data Analysis and Visualization software version 5.0.2 (32 bit). Comparison between groups were performed using one-way analysis of variance (ANOVA). $p<0.05$ was considered significant.

\section{Results}

Acute toxicity study

NOSE and NORE were administered to experimental animals up to $2000 \mathrm{mg} / \mathrm{kg}$ dose for evaluation of toxicity and selection of experimental doses. However, up to the highest dose, no signs of mortality or 
physiological discomfort were observed in the animals. Therefore, $1 / 40^{\text {th }}(50 \mathrm{mg} / \mathrm{kg})$ and $1 / 10^{\text {th }}(200 \mathrm{mg} / \mathrm{kg})$ of the highest dose were selected for the in vivo hepatoprotective experiments.

\section{Body and liver weight}

Significant change $(p<0.001)$ in body weight were observed in $\mathrm{CCl}_{4}$ and silymarin groups (Table 1). However, unlike all other groups, final body weight was decreased $(17.07 \pm 2.56 \%)$ only in case of $\mathrm{CCl}_{4}$ group. Similarly, compared to control, significant $(p<0.01)$ difference of liver weight $(5.32 \pm 0.18 \mathrm{~g})$ in $\mathrm{CCl}_{4}$ group was observed, which also resulted in highest relative liver weight $(32.53 \pm 3.03 \mathrm{~g})$ of the same group. Interestingly, among all groups, both the high dose groups prevented utmost percentage body weight change. However, the relative liver weight of all the groups were comparable, except $\mathrm{CCl}_{4}$ group.

\section{Liver marker enzymes and biochemical parameters (in vivo)}

Table 2 summarized the effect of $\mathrm{CCl}_{4}$ and subsequent treatment of silymarin and oleander extracts on the serum enzymatic and biochemical parameters in the experimental animals. The parameters were abnormally altered due to $\mathrm{CCl}_{4}$ exposure and subsequently normalized by treatments with silymarin and oleander extracts. Among all the parameters, only the levels of protein and albumin were lowered due to $\mathrm{CCl}_{4}$ treatment. The percentage change in the parameters are summarized in Additional file 2.

\section{Estimation of hepatic anti-oxidative enzymes: catalase and peroxidase}

The activities of catalase and peroxidase enzymes in hepatic tissue were significantly $(p<0.001)$ lowered as a result of $\mathrm{CCl}_{4}$ treatment (Fig. 1). The catalase and peroxidase activities in the control group were $6.83 \mathrm{mM} \mathrm{H}_{2} \mathrm{O}_{2}$ consumed $/ \mathrm{min} / \mathrm{mg}$ tissue and $12.99 \mathrm{Unit} / \mathrm{mg}$ tissue, which were lowered respectively to $3.58 \mathrm{mM} \mathrm{H}_{2} \mathrm{O}_{2}$ consumed/ $\mathrm{min} / \mathrm{mg}$ tissue and $6.32 \mathrm{Unit} / \mathrm{mg}$ tissue due to $\mathrm{CCl}_{4}$ administration. This resulted in 47.58 and 51.34 \% lowering of antioxidant enzymatic activities, respectively. The percentage change in catalase activities in the silymarin, NOSE high and NORE high groups were 58.56, 27.37 and 25.25 , respectively. Similarly, the percentage change in peroxidase levels were $46.20,18.19$ and 22.78 , respectively.

Liver marker enzymes and biochemical parameters (in vitro) The effects of silymarin and oleander extracts on the in vitro enzymatic and biochemical parameters are summarized in Table 3. The results demonstrated lowering of the parameters as a result of $\mathrm{CCl}_{4}$ toxicity. The total protein level was only elevated. However, the elevation was not significant enough $(p>0.05)$. The percentage change of the parameters are enlisted in Additional file 2.

\section{Lipid peroxidation (MDA content)}

The effects of $\mathrm{CCl}_{4}$ toxicity and subsequent treatment with plant extracts on the MDA content are represented in Fig. 2a. Initially the MDA content was elevated from $2.73 \pm 0.06 \mu \mathrm{M} / \mathrm{l}$ in control to $5.49 \pm 0.18 \mu \mathrm{M} / 1$ in $\mathrm{CCl}_{4}$ group, contributing to 2.01 fold elevation. However, the subsequent treatments resulted in 45.53, 20.76 and $21.12 \%$ decrease in blood MDA content respectively in silymarin, NOSE high and NORE groups.

\section{Cell viability}

$\mathrm{CCl}_{4}$ mediated direct cellular damage (Fig. 2b) was represented by significant $(p<0.001)$ difference $(61.92 \%)$ in cell viability between control and $\mathrm{CCl}_{4}$ group. However, the cell viability was improved by subsequent treatment with silymarin $(p<0.001)$ and the oleander extracts $(p<0.01)$. The extent of improvement of cell viability were $106.95,47.32$ and $51.60 \%$, respectively for in silymarin, NOSE high and NORE groups.

\section{Measurement of TNF- $\alpha$}

The levels of TNF- $\alpha$ in different groups are demonstrated in Fig. 2c. The level of TNF- $\alpha$ in control was $58 \pm$

Table 1 Changes of the body weight (g) and liver weight (g) in different experimental groups. Data represented as mean \pm SD of six observations

\begin{tabular}{lccllc}
\hline & Initial body weight & Final body weight & \% body weight change & Liver weight & Relative liver weight \\
\hline Control & $22.17 \pm 0.70$ & $24.23 \pm 0.99^{*}$ & $9.26 \pm 1.18 \boldsymbol{\Delta}$ & $4.37 \pm 0.21$ & $18.04 \pm 0.13$ \\
$C_{C l}$ & $21.10 \pm 0.34$ & $17.49 \pm 0.27^{* * *}$ & $17.07 \pm 2.56 \boldsymbol{\nabla}$ & $5.32 \pm 0.18^{* *}$ & $32.53 \pm 3.03$ \\
Silymarin & $21.64 \pm 0.19$ & $23.43 \pm 0.25^{* * *}$ & $8.29 \pm 1.39 \boldsymbol{\Delta}$ & $4.30 \pm 0.09^{\mathrm{NS}}$ & $18.37 \pm 0.22$ \\
NOSE low & $21.71 \pm 0.49$ & $22.36 \pm 0.67^{\mathrm{NS}}$ & $3.96 \pm 3.90 \boldsymbol{\Delta}$ & $4.59 \pm 0.16^{\mathrm{NS}}$ & $20.56 \pm 1.36$ \\
NOSE high & $22.25 \pm 0.38$ & $22.67 \pm 0.18^{\mathrm{NS}}$ & $1.89 \pm 2.38 \boldsymbol{\Delta}$ & $4.55 \pm 0.29^{\mathrm{NS}}$ & $20.05 \pm 1.18$ \\
NORE low & $22.14 \pm 0.38$ & $22.59 \pm 0.21^{\mathrm{NS}}$ & $2.25 \pm 2.02 \boldsymbol{\Delta}$ & $4.41 \pm 0.16^{\mathrm{NS}}$ & $19.50 \pm 0.58$ \\
NORE high & $22.20 \pm 0.57$ & $22.33 \pm 0.46^{\mathrm{NS}}$ & $1.48 \pm 0.26 \boldsymbol{\Delta}$ & $4.24 \pm 0.10^{\mathrm{NS}}$ & $19.00 \pm 0.52$ \\
\hline
\end{tabular}

${ }^{\mathrm{NS}} p>0.05,{ }^{*} p<0.05,{ }^{* *} p<0.01$ and ${ }^{* * *} p<0.001$. Final body weight was compared with initial body weight of corresponding group and liver weight of treated groups were compared with liver weight of control group. $\boldsymbol{\Delta}$ represents increase and $\boldsymbol{\nabla}$ represents decrease 
Table 2 Changes in the levels of various enzymatic and biochemical parameters of the serum samples of seven experimental groups. Data represented as mean \pm SD of six observations

\begin{tabular}{|c|c|c|c|c|c|c|c|}
\hline & Control & $\mathrm{CCl}_{4}$ & Silymarin & NOSE low & NOSE high & NORE low & NORE high \\
\hline ACP (K.A.) & $3.61 \pm 0.31$ & $10.94 \pm 1.04^{* * *}$ & $5.76 \pm 0.43^{* * b}$ & $10.01 \pm 0.61^{* * a d}$ & $8.75 \pm 0.44^{* * * c}$ & $9.64 \pm 0.31^{* * * d}$ & $8.55 \pm 0.32^{* * * c}$ \\
\hline ALP (K.A.) & $10.86 \pm 1.29$ & $28.44 \pm 1.25^{* * *}$ & $12.93 \pm 0.80^{\mathrm{NS} a}$ & $24.92 \pm 2.27^{* * * d}$ & $22.21 \pm 2.45^{* * a}$ & $24.56 \pm 0.95^{* * * c}$ & $22.10 \pm 1.45^{* * * b}$ \\
\hline AST (U/ml) & $65.88 \pm 3.74$ & $137.28 \pm 2.95^{* * *}$ & $74.01 \pm 0.16^{\mathrm{NS} \mathrm{a}}$ & $121.27 \pm 2.89^{* * * a}$ & $99.19 \pm 5.48 * * * b$ & $117.93 \pm 6.30^{* * * b}$ & $110.25 \pm 5.00^{* * * b}$ \\
\hline ALT (U/ml) & $42.63 \pm 1.4$ & $126.26 \pm 4.88^{* * *}$ & $53.81 \pm 3.15^{* * a}$ & $109.27 \pm 4.21^{* * * c}$ & $81.27 \pm 7.66^{* * d}$ & $119.23 \pm 6.40^{* * * d}$ & $95.94 \pm 10.39 * * * c$ \\
\hline GGT (U/I) & $2.51 \pm 0.36$ & $6.06 \pm 0.23^{* * *}$ & $3.35 \pm 0.12^{* a}$ & $5.48 \pm 0.33^{* * * d}$ & $4.9 \pm 0.36^{* * c}$ & $5.5 \pm 0.25^{* * * c}$ & $4.48 \pm 0.24^{* * b}$ \\
\hline Glucose (mg/dl) & $53.53 \pm 1.28$ & $80.38 \pm 1.55^{* * *}$ & $55.23 \pm 3.48^{\mathrm{NS} a}$ & $76.40 \pm 4.71^{* * d}$ & $63.39 \pm 1.42^{* * * a}$ & $74.96 \pm 2.95^{* * * \mathrm{c}}$ & $65.86 \pm 3.43^{* * b}$ \\
\hline Protein (g/dl) & $4.77 \pm 0.29$ & $3.10 \pm 0.23^{* *}$ & $4.94 \pm 0.05^{\mathrm{NS} \mathrm{a}}$ & $3.29 \pm 0.21^{* * d}$ & $4.19 \pm 0.24^{\mathrm{NS} \mathrm{b}}$ & $3.62 \pm 0.13^{* * c}$ & $3.88 \pm 0.07^{* * b}$ \\
\hline Albumin (g/dl) & $3.18 \pm 0.07$ & $1.42 \pm 0.13^{* * *}$ & $2.86 \pm 0.17^{* a}$ & $1.53 \pm 0.27 * * * d$ & $1.96 \pm 0.22^{* * * a}$ & $1.55 \pm 0.09^{* * *}$ NS & $1.71 \pm 0.26^{* * * \mathrm{NS}}$ \\
\hline Globulin (g/dl) & $1.59 \pm 0.30$ & $1.68 \pm 0.12^{\mathrm{NS}}$ & $2.11 \pm 0.17^{N S C}$ & $1.76 \pm 0.28^{\mathrm{NS} d}$ & $2.23 \pm 0.03^{* b}$ & $2.06 \pm 0.12^{\mathrm{NS} C}$ & $2.17 \pm 0.20^{N S C}$ \\
\hline Bilirubin (mg/dl) & $0.41 \pm 0.03$ & $1.15 \pm 0.04^{* * *}$ & $0.51 \pm 0.02^{* a}$ & $1.01 \pm 0.03^{* * * b}$ & $0.91 \pm 0.06^{* * * b}$ & $1.11 \pm 0.07^{* * * d}$ & $1.01 \pm 0.02 * * * b$ \\
\hline Urea (mg/dl) & $20.58 \pm 2.39$ & $111.84 \pm 3.54^{* * *}$ & $35.25 \pm 6.78^{* a}$ & $106.83 \pm 3.23^{* * * d}$ & $75.67 \pm 5.59^{* * * a}$ & $89.96 \pm 3.77^{* * * \mathrm{~b}}$ & $67.71 \pm 7.43^{* * * a}$ \\
\hline LDH (U/I) & $219.16 \pm 7.19$ & $526.97 \pm 7.97^{* * *}$ & $288.44 \pm 10.99^{* * * a}$ & $511.31 \pm 6.73^{* * * d}$ & $433.8 \pm 17.47^{* * * b}$ & $495.13 \pm 12.21^{* * * c}$ & $472.24 \pm 12.07^{* * * b}$ \\
\hline $\begin{array}{l}\text { Cholesterol } \\
(\mathrm{mg} / \mathrm{dl})\end{array}$ & $78.86 \pm 3.49$ & $134.52 \pm 0.78^{* * *}$ & $105.62 \pm 3.36^{* * * a}$ & $122.00 \pm 5.39^{* * * a}$ & $114.62 \pm 5.39 * * * b$ & $124.96 \pm 5.38 * * * d$ & $113.48 \pm 6.80^{* * b}$ \\
\hline
\end{tabular}

${ }^{\text {NS }} p=$ non-significant $(p>0.05),{ }^{*} p<0.05,{ }^{* *} p<0.01$ and ${ }^{* * *} p<0.001$ vs control ${ }^{d} \mathrm{p}=$ non-significant $(p>0.05),{ }^{c} p<0.05,{ }^{b} p<0.01$ and ${ }^{\mathrm{a}} p<0.001 \mathrm{vs} \mathrm{CCl}_{4}$ group

$20.22 \mathrm{pg} / \mathrm{ml}$, which was 18.54 fold increased to $1075.66 \pm$ $61.53 \mathrm{pg} / \mathrm{ml}$ due to $\mathrm{CCl}_{4}$ toxicity. However, the TNF- $\alpha$ level was subsequently lowered to 43.19, 71.33 and $61.60 \%$ in silymarin, NOSE high and NORE high groups respectively, compared to $\mathrm{CCl}_{4}$ group. All the extract treated groups demonstrated higher TNF- $\alpha$ inhibitory activities than the silymarin group.

\section{Inhibition of nitric oxide}

$\mathrm{CCl}_{4}$ toxicity resulted in 3.22 fold increase in $\mathrm{NO}$ release compared to control (Fig. 2d). However, significant $(p<$ 0.001 ) lowering of NO level was observed in the treated groups. The NO level in silymarin, NOSE high and NORE high groups were $111.88 \pm 8.60,142.89 \pm 8.72$ and $161.24 \pm 7.39 \%$ respectively, when NO release of control was considered as $100 \%$. This resulted in $0.34,0.44$ and 0.50 fold lowering of NO level.

\section{Histopathological studies}

The extent of liver damage caused by haloalkane toxicity was clearly evident through the haematoxylin-eosin staining in the histopathological studies (Figs. 3 and 4). The normal hepatic architecture in the control could be described by presence of intact spherical nucleus, healthy cellular architecture, well preserved hepatocellular symmetry, marked cellular boundaries, and clear cytoplasm. Extensive hepatocellular damage in the $\mathrm{CCl}_{4}$ group could be described through the presence of dilated sinusoids, fatty infiltration and deformed cellular margins. Extensive sings of inflammation was visible in terms of infiltration of
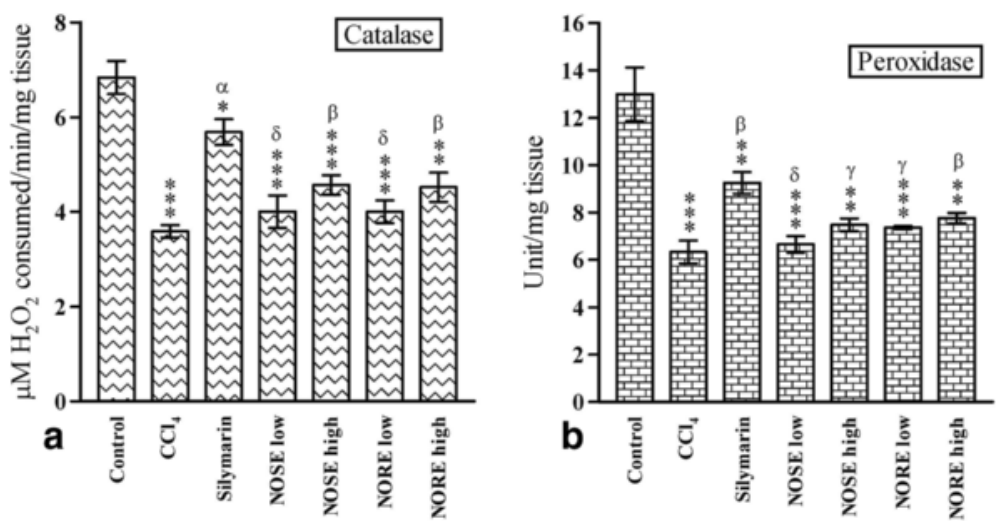

Fig. 1 The effect of oleander extracts on the $\mathbf{a}$ Catalase and $\mathbf{b}$ Peroxidase activities in $\mathrm{CCl}_{4}$ intoxicated liver samples. Data represented as Mean \pm SD of six observations. ${ }^{*} p<0.05,{ }^{* *} p<0.01$ and ${ }^{* *} p<0.001$ Vs control group. $\delta=p>0.05, \gamma=p<0.05, \beta=p<0.01$ and $a=p<0.001$ Vs CCl group 
Table 3 Changes in the levels of various enzymatic and biochemical parameters of the culture supernatants of the experimental groups. Data represented as mean \pm SD of six observations

\begin{tabular}{|c|c|c|c|c|c|c|c|}
\hline Parameters (unit) & Control & $\mathrm{CCl}_{4}$ & Silymarin & NOSE low & NOSE high & NORE low & NORE high \\
\hline ACP (K.A.) & $0.71 \pm 0.10$ & $1.74 \pm 0.11^{* * *}$ & $1.17 \pm 0.16^{* b}$ & $1.58 \pm 0.12^{* * * d}$ & $1.48 \pm 0.08^{* * * c}$ & $1.61 \pm 0.15^{* * d}$ & $1.40 \pm 0.16^{* * c}$ \\
\hline ALP (K.A.) & $3.09 \pm 0.11$ & $7.51 \pm 0.33^{* * *}$ & $4.13 \pm 0.25^{* * a}$ & $6.79 \pm 0.24^{* * * c}$ & $5.91 \pm 0.27^{* * * b}$ & $6.99 \pm 0.37^{* * * d}$ & $6.09 \pm 0.50^{* * * c}$ \\
\hline AST (U/ml) & $14.87 \pm 0.72$ & $44.49 \pm 0.75^{* * *}$ & $16.39 \pm 1.41^{\mathrm{NS} \mathrm{a}}$ & $43.86 \pm 2.60^{* * * d}$ & $36.32 \pm 1.21^{* * * a}$ & $38.06 \pm 3.76^{* * * c}$ & $29.53 \pm 3.22 * * b$ \\
\hline ALT (U/ml) & $5.81 \pm 0.15$ & $27.55 \pm 0.52^{* * *}$ & $10.57 \pm 0.29 * * * a$ & $26.33 \pm 1.29^{* * * d}$ & $22.17 \pm 2.40^{* * * c}$ & $24.47 \pm 1.82^{* * * \mathrm{c}}$ & $20.77 \pm 1.63^{* * * b}$ \\
\hline GGT (U/I) & $0.59 \pm 0.04$ & $0.78 \pm 0.02^{* *}$ & $0.58 \pm 0.01^{\mathrm{NS}} \mathrm{a}$ & $0.77 \pm 0.01^{* * d}$ & $0.71 \pm 0.03^{* d}$ & $0.74 \pm 0.00^{* * d}$ & $0.72 \pm 0.01^{* * c}$ \\
\hline Bilirubin (mg/dl) & $0.13 \pm 0.00$ & $0.53 \pm 0.05^{* * *}$ & $0.17 \pm 0.00^{* * a}$ & $0.56 \pm 0.14^{* * b}$ & $0.40 \pm 0.02 * * * b$ & $0.465 \pm 0.02^{* * * d}$ & $0.43 \pm 0.02^{* * d}$ \\
\hline Protein $(\mathrm{g} / \mathrm{dl})$ & $6.48 \pm 0.75$ & $5.3 \pm 0.26^{\mathrm{NS}}$ & $5.7 \pm 0.42^{\text {NS d }}$ & $5.61 \pm 0.23^{\mathrm{NS} d}$ & $6.05 \pm 0.15^{\mathrm{NS} C}$ & $5.77 \pm 0.12^{\mathrm{NS} C}$ & $6.02 \pm 0.21^{\text {NS C }}$ \\
\hline LDH (U/I) & $35.94 \pm 29.66$ & $181.33 \pm 11.24^{* *}$ & $94.16 \pm 7.34^{* a}$ & $138.59 \pm 14.05^{* * c}$ & $105.00 \pm 10.02 * a$ & $144.40 \pm 11.49^{* * c}$ & $114.87 \pm 10.53^{* b}$ \\
\hline
\end{tabular}

${ }^{\mathrm{NS}} \mathrm{p}=$ non-significant $(p>0.05),{ }^{*} p<0.05,{ }^{* *} p<0.01$ and ${ }^{* * *} p<0.001$ vs control

${ }^{d} p=$ non-significant $(p>0.05),{ }^{c} p<0.05,{ }^{b} p<0.01$ and ${ }^{a} p<0.001$ vs $\mathrm{CCl}_{4}$ group

leukocytes in the $\mathrm{CCl}_{4}$ group. Moreover, vascular congestions and scattered regions of hepatic fibrosis marked the intensive $\mathrm{CCl}_{4}$ mediated toxicity. The signs of hepatic damage were also visible in the silymarin and extract treated groups, however the extent of damage was much lower than the $\mathrm{CCl}_{4}$ group. Liver samples of NOSE and NORE high groups possessed much lover frequency of necrotic nucleus, dilated sinusoids, infiltrated leukocytes, deformed cellular architecture and vascular congestions.
This demonstrated amelioration of haloalkane induced liver damage by the oleander extracts.

\section{FTIR and GC-MS analysis}

FTIR analysis of NOSE and NORE (Fig. 5) were performed to identify the predominant chemical groups present in the extracts. The IR spectrums displayed different peaks (Additional file 3) at corresponding to different functional groups [24].
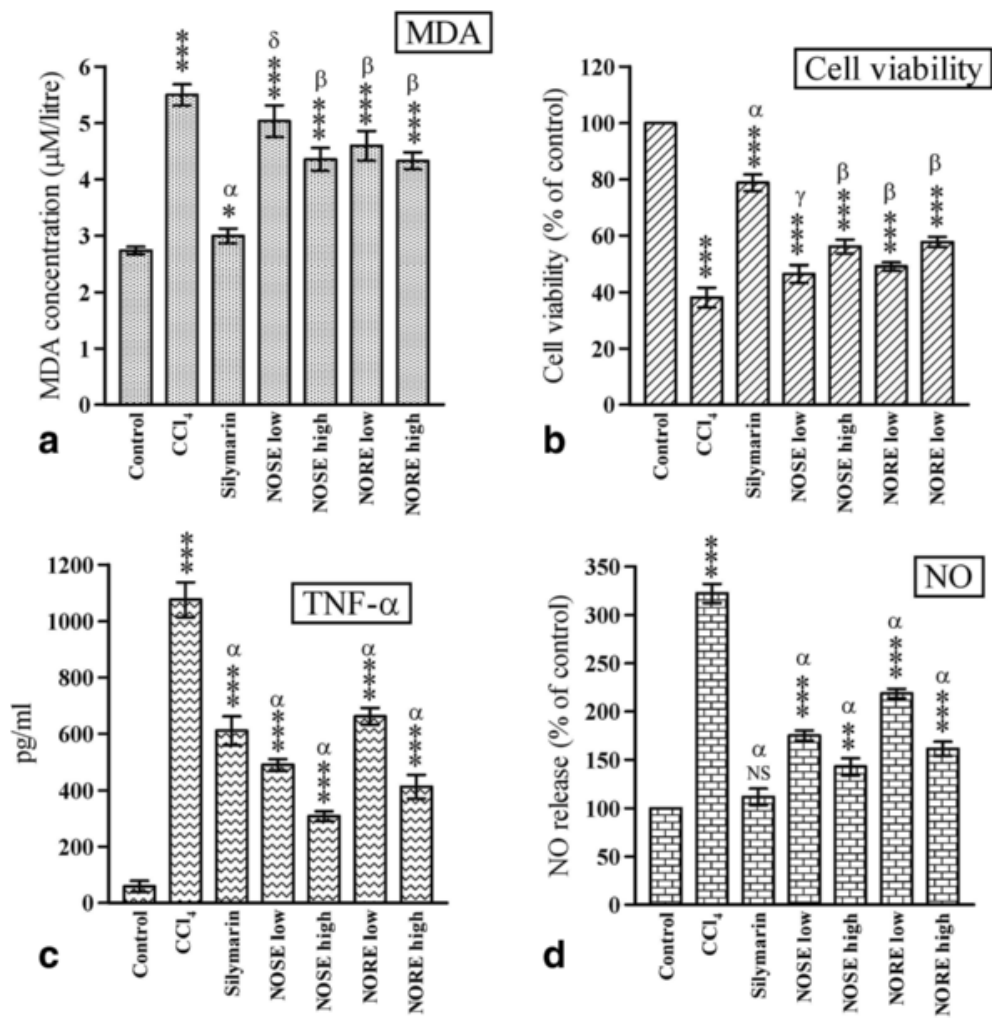

Fig. 2 The effects of oleander extract on a MDA level, $\mathbf{b}$ Cell viability, c TNF-a level and $\mathbf{d}$ NO release. Data represented as Mean \pm SD of six observations. ${ }^{*} p<0.05,{ }^{* *} p<0.01$ and ${ }^{* * *} p<0.001$ Vs control group. $\delta=p>0.05, \gamma=p<0.05, \beta=p<0.01$ and $a=p<0.001 \mathrm{Vs}_{\mathrm{S}} \mathrm{CCl}_{4} \mathrm{group}$ 

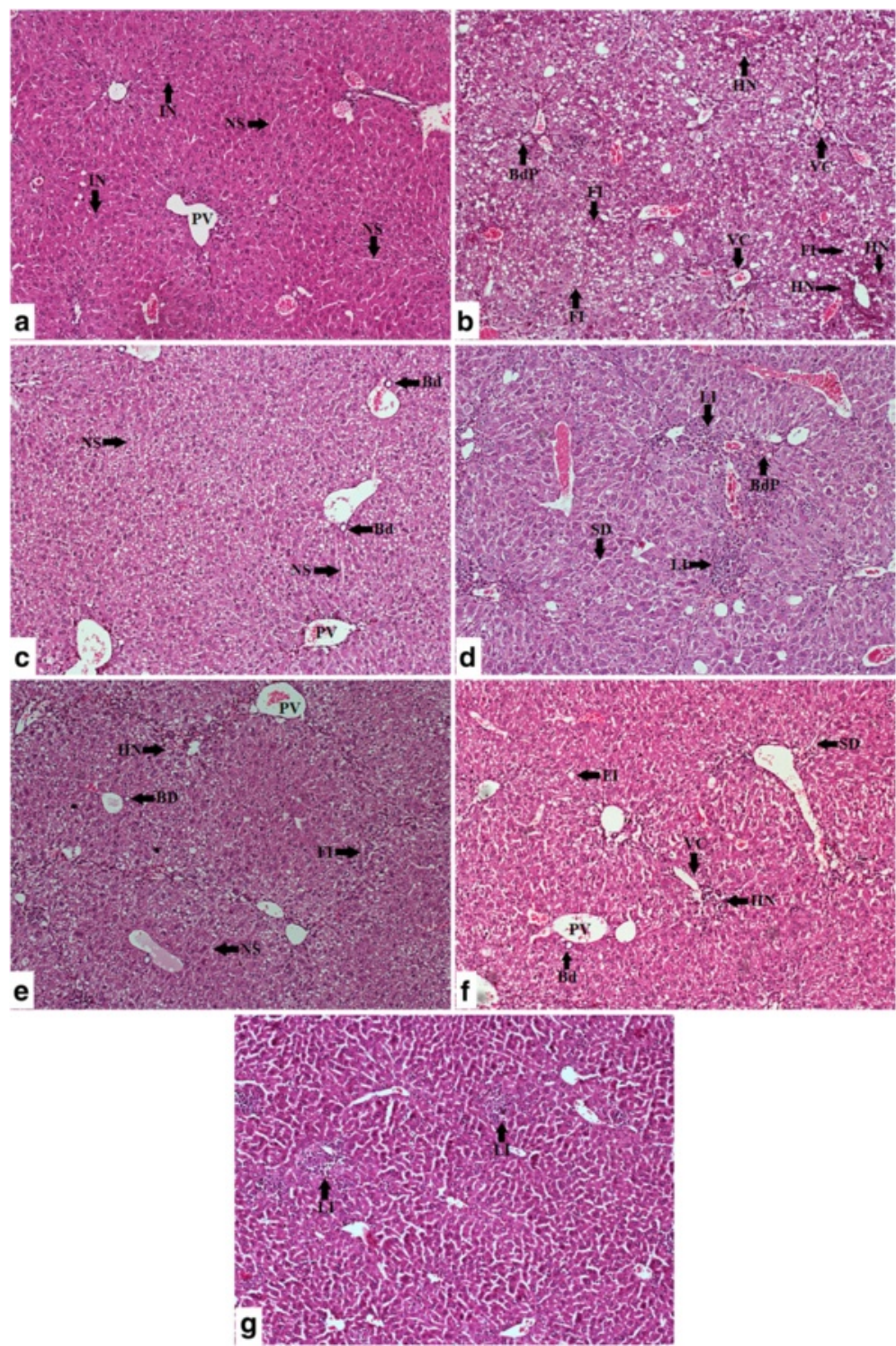

Fig. 3 Photomicrographs (100x) of the histopathological examinations of the liver samples of different groups. Even though the extract treated groups possessed injury marks however, the extent of signs of injury were much lower in the extract treated groups compared to $\mathrm{CCl}_{4}$ group. a Control group liver demonstrated normal liver architecture with normal sinusoids (NS), hepatocytes with intact nucleus (IN), un-inflamed portal vein (PV). $\mathbf{b} \mathrm{CCl}_{4}$ group liver demonstrated significant loss of hepatocellular architecture with extensive fatty infiltration (FI) leading to steatosis, bile duct proliferation (BdP), vascular congestion (VC) and haemorrhagic necrosis (HN) around portal vein. Loss of hepatic nodular structure and disorganized hepatocytes marked the $\mathrm{CCl}_{4}$ induced liver damage. $\mathbf{c}$ Silymarin group demonstrated hepatoprotective activity by substantial amendment of proliferated bile duct (Bd) with normal sinusoids (NS) and intact portal veins (PV). $\mathbf{d}$ NOSE low group was marked by less leukocyte infiltrations (LI), sinusoidal dilations (SD) and bile duct proliferation (BdP). e NOSE high group reflected comparatively less haemorrhagic necrosis $(\mathrm{HN})$ and fatty infiltrations (FI). f NORE low group also showed traces of sinusoidal dilations (SD), haemorrhagic necrosis (HN) and fatty infiltration (FI). g NORE high group demonstrated lowering of most of the injury signs however, leukocyte infiltrations (LI) could be identified in the liver samples

NOSE and NORE were bi-fractionated and subjected to GC-MS analysis. The analysis identified (Fig. 6 and Additional file 4) several bioactive constituents in the oleander extracts such as vanillin, trans- isoeugenol, murrayafoline A, apocynin, squalene, $\beta$-amyrin, lupeol, tocopherol etc.

\section{Discussion}

The toxicity profile of $\mathrm{CCl}_{4}$ has been thoroughly studied and is well established [25-27]. $\mathrm{CCl}_{4}$ has a rich history of environmental toxicity and occupational hazard due to its extensive use in industrial sectors. This had led to an awareness in the industrial and domestic use of $\mathrm{CCl}_{4}$ 

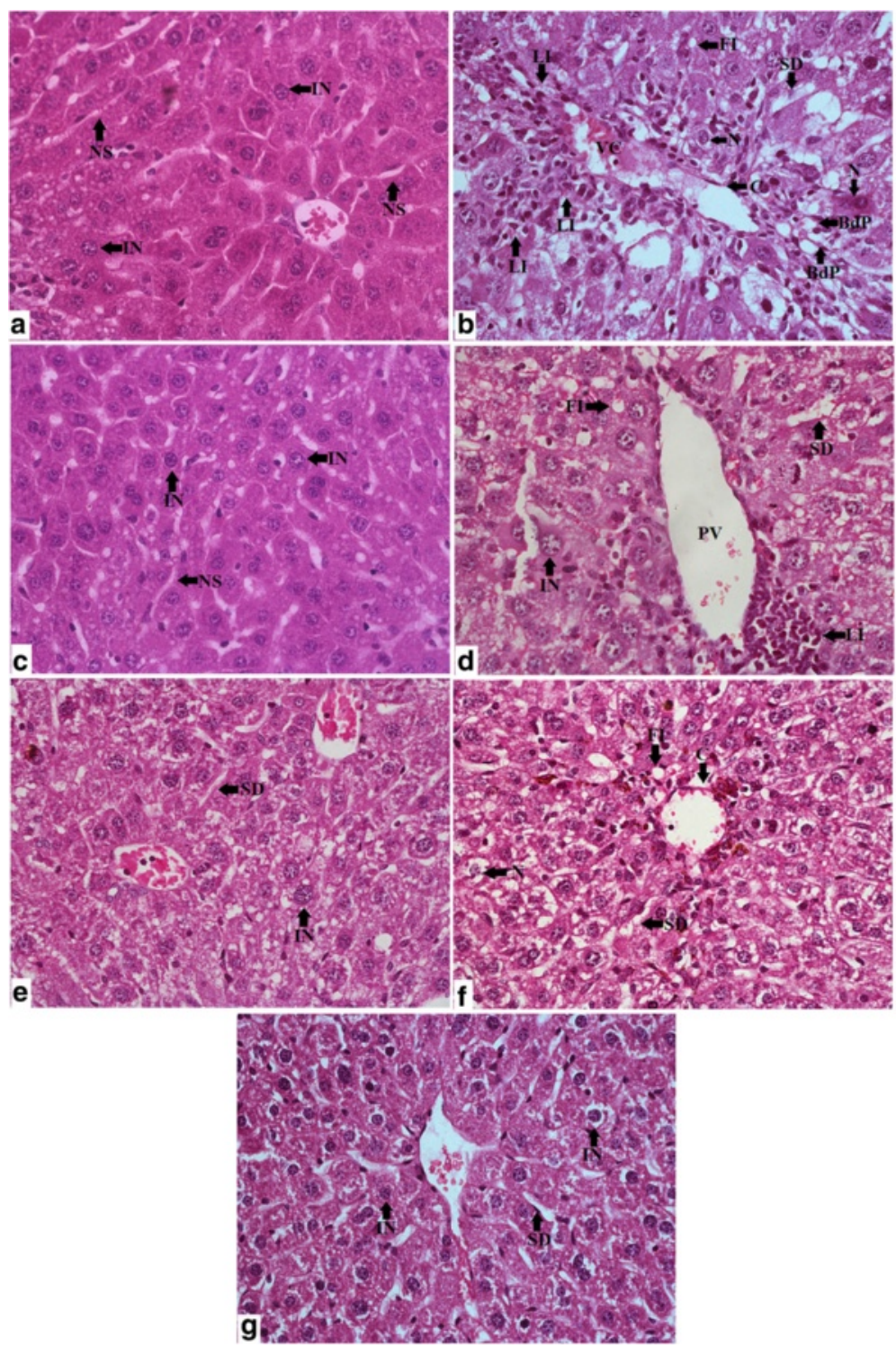

Fig. 4 Photomicrographs (400X) of the histopathological examinations of the liver samples of different groups. a Control group liver sampled possessed well packed hepatocytes with intact nucleus (IN) and normal sinusoids (NS). $\mathbf{b} \mathrm{CCl}_{4}$ group liver possessed extensive fatty infiltrations $(\mathrm{Fl})$, Necrotic hepatocytes $(\mathrm{N})$, prominent signs of inflammation with leukocyte infiltrations (LI), prominent calcification (C) around the congested vesicles (VC) with bile duct proliferations (BdP). c Silymarin group liver samples were characterized with normal sinusoids (NS) and intact nucleus (IN) containing healthy hepatocytes. d NOSE low group demonstrated lower fatty infiltrations (FI), sinusoidal dilations (SD) and leukocyte infiltrations (LI). e NOSE high group resulted in renewal of normal hepatic architecture with several hepatocytes with intact nucleus (IN) and lowered sinusoidal dilations (SD). f NORE low group livers possessed few necrotic (N) cells, fatty infiltrations (FI) and zonal calcification (C) around the portal veins (PV). $\mathbf{g}$ NOSE high group showed near to normal hepatic architecture with predominantly intact nucleus (IN) containing normal hepatocytes and undiluted normal sinusoids (NS)

from the early 70's, leading to a ban on production and import of $\mathrm{CCl}_{4}$ in 1996 [28]. However, $\mathrm{CCl}_{4}$ continues to play an essential role as a model haloalkane xenobiotic in the pharmaco-toxicological studies. $\mathrm{CCl}_{4}$ induced liver damage is primarily initiated by the formation of trichloromethyle radical $\left(\mathrm{CCl}_{3}{ }^{\bullet}\right)$ due to cytochrome P450 mediated reductive dehalogenation of $\mathrm{CCl}_{4}[8,29]$. Persistent formation of the highly reactive $\mathrm{CCl}_{3}{ }^{\bullet}$ in the liver cause steatosis, lipid peroxidation leading to hepatocarcinoma [8]. Additionally, fusion of $\mathrm{CCl}_{3}{ }^{\bullet}$ with diatomic oxygen generates highly reactive trichloromethylperoxy radical $\left(\mathrm{CCl}_{3} \mathrm{OO}^{\bullet}\right)$ which further causes damage to mitochondria, endoplasmic reticulum and plasma membrane permeability, resulting in loss of cytosolic $\mathrm{Ca}^{2+}$ sequestration and homeostasis [8]. The present study demonstrated that, antioxidant rich oleander extracts hold the 

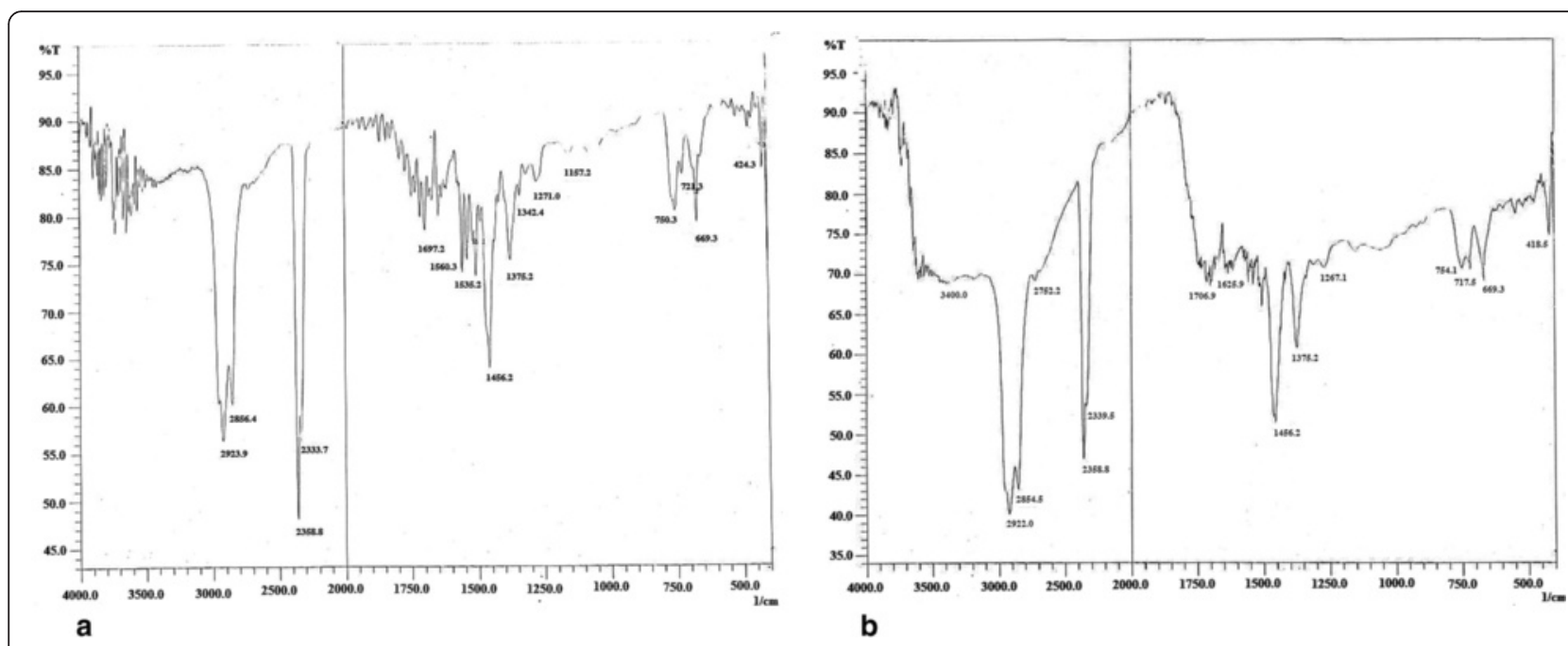

Fig. 5 Fourier transform infrared spectra of a NOSE and $\mathbf{b}$ NORE

potentiality to ameliorate $\mathrm{CCl}_{4}$ induced hepatotoxicity in murine model. The data were further supported by the identification of several phytochemical constituents with well-established hepatoprotective potentialities.

$\mathrm{CCl}_{4}$ toxicity caused significant $(p<0.001)$ loss of body weight as well as highest relative liver weight in the animals. Compared to control and silymarin group, the final body weight change in the extract treated groups were much less. This may presumably indicate the potentiality of oleander extracts to restrict body weight increase through anti-hyperlipidemic activity as demonstrated previously by body weight lowering capability of oleander [30]. Compared to control, 1.80 fold higher relative liver weight in the $\mathrm{CCl}_{4}$ group reflected formation of fatty liver

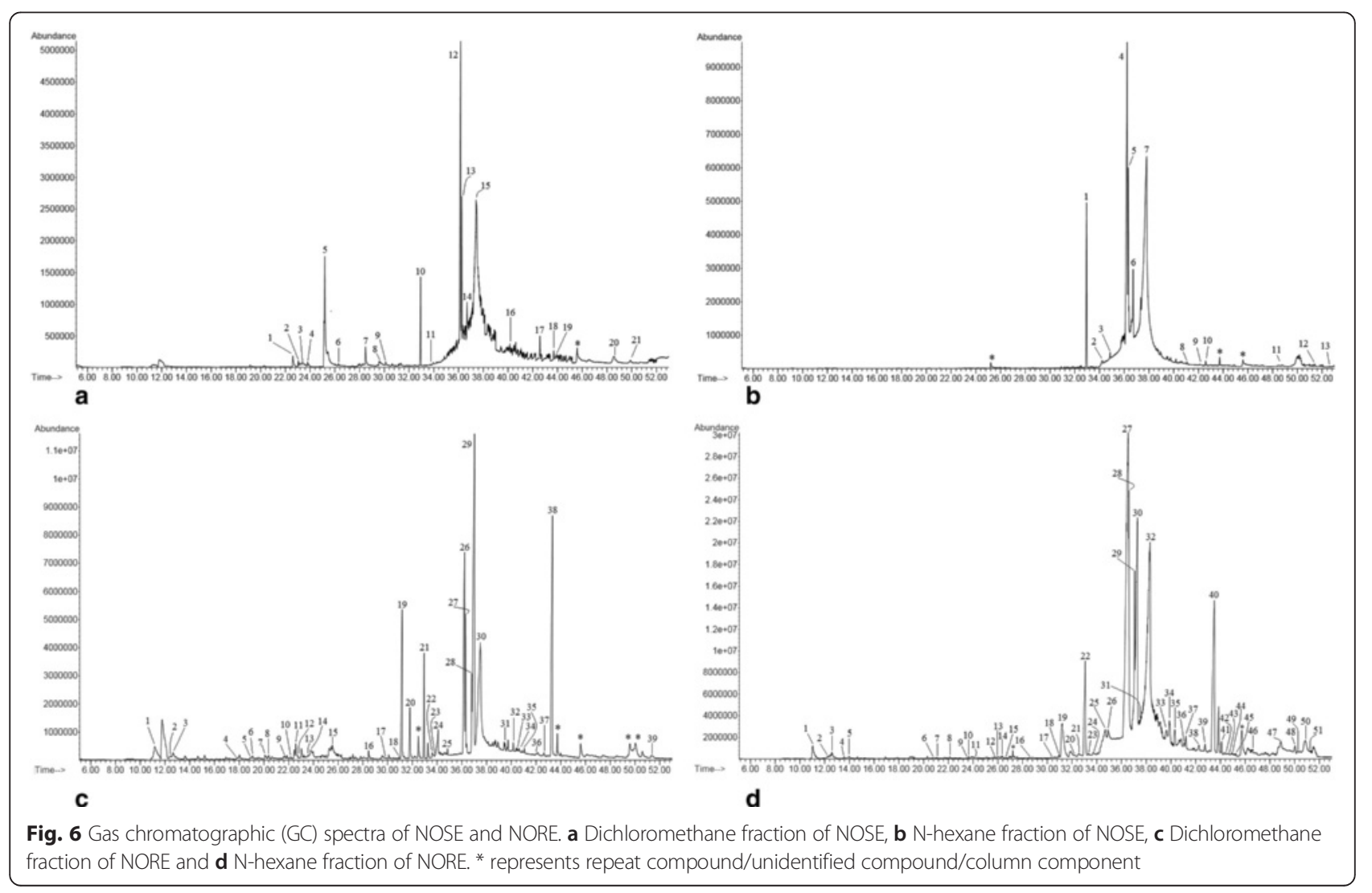




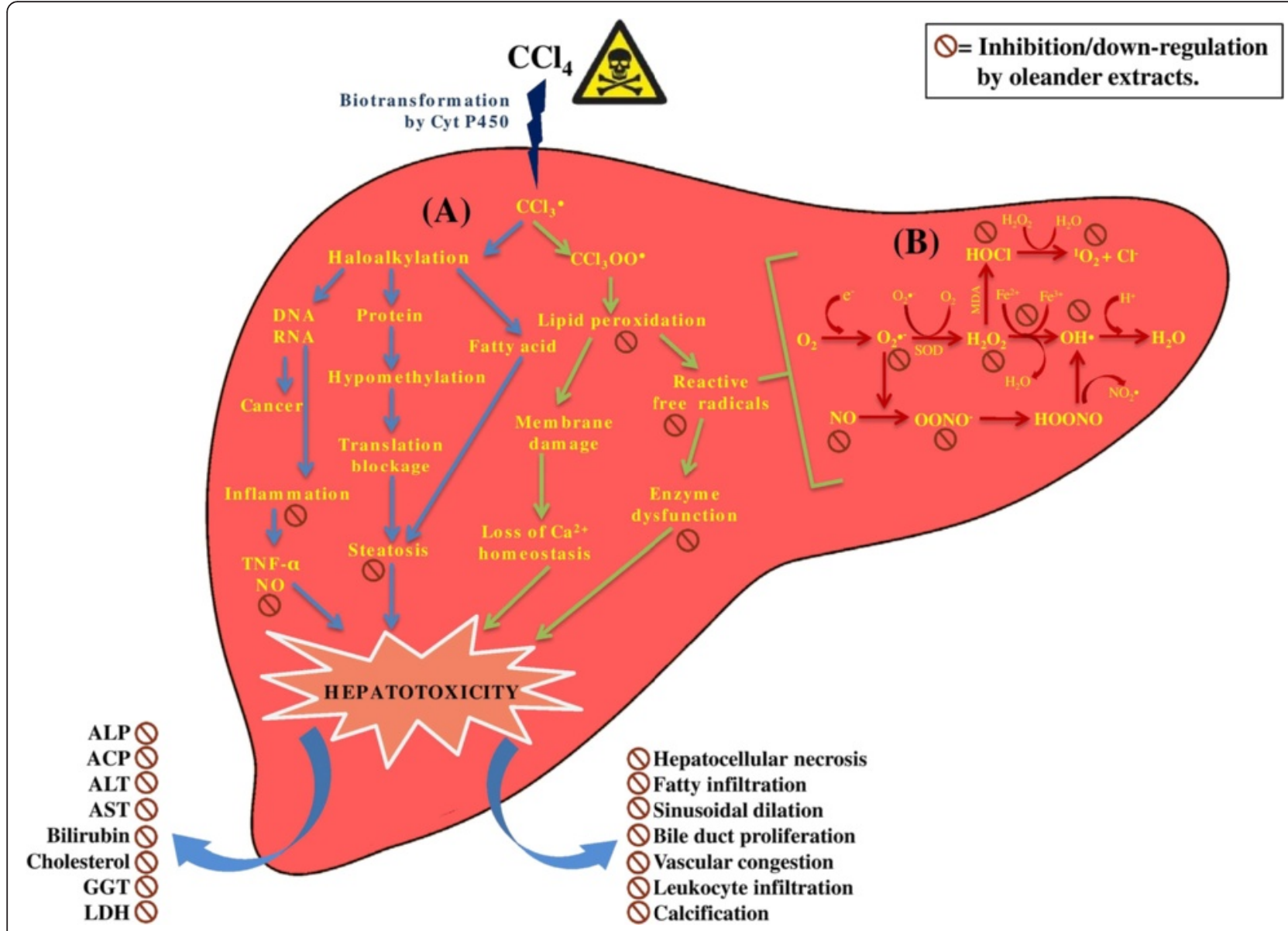

Fig. 7 Schematic representation of the mode of action of oleander extracts to ameliorate $\mathrm{CCl}_{4}$ induced hepatotoxicity. Section (A) demonstrates the mechanism of $\mathrm{CCl}_{4}$ induced hepatotoxicity which is predominantly mediated by oxidative stress and inflammatory injury due to the formation of reactive metabolic intermediates. Cyt P450 = cytochrome $\mathrm{P} 450, \mathrm{CCl}_{3}{ }^{\bullet}=$ trichloromethyle radical, $\mathrm{CCl}_{3} \mathrm{OO}{ }^{\bullet}=$ trichloromethylperoxy radical, TNF- $a=$ tumor necrosis factor-a, $\mathrm{NO}=$ nitric oxide. Section (B) represents the free radical formation cascade during xenobiotic induced hepatotoxicity causing oxidative and nitrosative stress. $\mathrm{CCl}_{4}$ induced hepatic damage distorts normal liver architecture and leads to leakage of liver marked enzymes into the blood stream. $\mathrm{OH}^{\bullet}=$ hydroxyl radical, $\mathrm{O}_{2}{ }^{\bullet-}=$ superoxide radical, $\mathrm{MPO}=$ myeloperoxidase, $\mathrm{ONOO}^{-}=$peroxynitrite, $\mathrm{HOONO}=$ peroxynitrous acid, $\mathrm{NO}_{2}{ }^{\bullet}=$ nitrogen dioxide radical, ${ }^{1} \mathrm{O}_{2}=$ singlet oxygen, $\mathrm{H}_{2} \mathrm{O}_{2}=$ hydrogen peroxide, $\mathrm{SOD}=$ Superoxide dismutase, $\mathrm{HOCl}=$ hypochlorous acid

which was further supported by increased blood cholesterol level and extensive steatosis throughout the $\mathrm{CCl}_{4}$ intoxicated liver samples. However, comparatively lower relative liver weight associated with insignificant total body weight change demonstrated the potentiality of oleander extracts to prevent severe physiological consequences due to $\mathrm{CCl}_{4}$ poisoning.

The altered levels of hepatobillary enzymes transaminase and phosphatase along with other enzymatic and biochemical parameters serve as biomarkers of hepatotoxicity whereas, normalization of the parameters represents improvement of normal liver functions [31-33]. $N$. indicum leaf extract has previously been shown to normalize similar liver biomarkers under $\mathrm{CCl}_{4}$ toxicity [14]. Moreover, oleander floral extracts normalized the elevated AST, GGT, ALT, LDH, ALP and creatinine levels in blood under isoproterenol-induced oxidative stress in rats [34]. Furthermore, the anti-hyperlipidemic activities were evident through lowering of cholesterol levels and associated lowering of fatty infiltrations and steatosis under the histopathological studies, which were further supported by the previous studied of Gayathri et al. [30]. The blood glucose level lowering capacity of the oleander extracts is also supported by its ethnopharmacological claim of hypoglycaemic activities as well as a recent study that demonstrated anti-diabetic activities of oleander leaf under alloxan induced diabetes in mouse [35]. $\mathrm{CCl}_{4}$ toxicity in the present study, resulted in significant $(p<0.001)$ elevation of ACP, ALP, AST, ALT, GGT, LDH, glucose, urea, globulin, bilirubin and cholesterol levels, signifying liver injury. Only the protein and albumin levels were decreased compared to control. The parameters were subsequently normalized up to certain extent due to silymarin and oleander extract treatments. 
Oleander extracts were further evaluated through primary culture to ameliorate $\mathrm{CCl}_{4}$ induced toxicity in mouse hepatocytes in vitro. Cultured liver cells are biochemically prototypical to intact hepatic system and therefore, serves as a model for evaluation of in vitro hepatotoxicity [8]. The results of in vitro studies demonstrated hepatoprotective potentialities of the extracts by normalization of the liver enzymatic and biochemical parameters as well. Liver, in spite of having the highest regenerative capacity, persistent exposure to cytochrome P450 activated organic xenobiotics and their reactive metabolic intermediates [36] cause tremendous hepatocellular necrosis. Necrotic hepatocytes with fragmented nucleus and distorted cellular margins were clearly evident through histopathological observations. Zonal haemorrhagic necrosis around portal veins in the $\mathrm{CCl}_{4}$ group signified that the hepatocellular injury had exceeded the regenerative power of the liver. This was further confirmed through MTT cell viability assay which showed $61.92 \%$ loss of cell viability due to direct $\mathrm{CCl}_{4}$ exposure in the culture medium. However, subsequent treatment with silymarin and oleander extracts prevented further hepatocellular damage resulting in significantly $(p<0.001)$ increase in viable cells compared to $\mathrm{CCl}_{4}$ group.

Xenobiotic intoxicated liver encounters a plethora of free radicals and reactive metabolic intermediates which results in great damage to cellular components and the extent of free radical medicated damage is proportional to the extent of lipid peroxidation [37-39]. The resultant oxidative stress further deactivates the cellular antioxidative enzymes [40]. Peroxidase and catalase are two major antioxidative enzymes responsible for the neutralization of free radicals. Peroxidase reduces and converts hydroperoxides and lipid peroxides into non-reactive species, whereas catalase prevents the formation of highly reactive $\mathrm{OH}^{\bullet}$ by scavenging $\mathrm{H}_{2} \mathrm{O}_{2}$ which participates in the Fenton reaction. Inhibition of both enzymatic activities accumulates $\mathrm{O}_{2}{ }^{\bullet-}$ and $\mathrm{H}_{2} \mathrm{O}_{2}$ which accentuate a cascade of free radical formation. $\mathrm{CCl}_{4}$ derived trichloromethylperoxy radical $\left(\mathrm{CCl}_{3} \mathrm{OO}^{\bullet}\right)$ abstracts proton from polyunsaturated fatty acids in the biological membranes and cause lipid peroxidation [8]. The reactive carbonyl compound MDA is a biomarker for oxidative damage and subsequent lipid peroxidation. The $70 \%$ hydromethanolic extracts of oleander previously demonstrated potent free radical scavenging activities by inhibiting some of the most harmful free radicals such as $\mathrm{OH}^{\bullet}, \mathrm{O}_{2}{ }^{--}$, NO, $\mathrm{ONOO}^{-}, \mathrm{H}_{2} \mathrm{O}_{2}$ and ${ }^{1} \mathrm{O}_{2}$ [11]. The study further showed that oleander extracts hold the ability to prevent Fenton reaction by means of neutralization of hydroperoxides and also inhibit lipid peroxidation by scavenging $\mathrm{OH}^{\bullet}$ directly. Lipid membranes are vulnerable to oxidative and nitrosative stress due to high amount of polyunsaturated fatty acids and transition metals. Transition metals such as iron are capable of damaging nuclear proteins, DNA, inhibit enzymes and degrade lipid membrane through oxidative Haber-Weiss reaction [41-43]. Our previous study showed potent iron chelation ability by the oleander extracts [11]. Recent studies also showed that $70 \%$ hydromethanolic extract of $N$. indicum leaf could ameliorate hemochromatosis and fibrosis in liver due to its potent antioxidant and iron chelation activities [13, 14]. Thus, the present study corroborates the previous findings of the antioxidative protection by oleander extracts. Lowering of liver antioxidative enzymes due to $\mathrm{CCl}_{4}$ toxicity marked increased oxidative stress, resulting in the elevation of lipid peroxidation. However, the diminished catalase and peroxidase levels and elevated MDA level were subsequently normalized by NOSE and NORE administration. The present observations thus, remains in accordance with the previous reports showing improvement of inhouse antioxidative enzymes by oleander leaf and flower extracts under oxidative stress [34, 44].

Liver diseases are accompanied by inflammatory conditions which accentuate the progression of liver failure. TNF- $\alpha$ and NO play a major role as pro-inflammatory mediators during $\mathrm{CCl}_{4}$ mediated liver injury which leads towards apoptotic cell death and fibrosis $[8,45]$. Under such xenobiotic induced hepatotoxic conditions, activated Kupffer cells secret a vast array of cytokines (TNF$\alpha$, IL-1, IL-8, IL-6), chemokines (KC/GRO, IP-109, MIP2, MCP-1) and pro-inflammatory mediators such as NO, which initiate hepatic inflammation and induce toxicity either by direct cellular damage or by chemoacttracting neutrophils and lymphocytes [46]. TNF- $\alpha$ initiates hepatotoxicity and fibrogenesis and overproduction of $\mathrm{NO}$ results in endotoxin shock and inflammatory hepatic injury $[45,47,48]$. Inducible nitric oxide synthase (iNOS) in liver parenchymal and non-parenchymal cells are induced by TNF- $\alpha$ resulting in nitrosative stress. In liver mitochondria, $\mathrm{O}_{2}{ }^{\bullet-}$ couples with an excess of $\mathrm{NO}$ to generate the highly reactive $\mathrm{ONOO}^{-}$. Interestingly, the anti-inflammatory activity of oleander extract is well known in traditional medicine and the extracts are also used in the treatment of diverse inflammatory disorders [17, 49]. In a preliminary study, Erdemoglu et al. [50] demonstrated anti-inflammatory activities of ethanolic and aqueous extracts of oleander leaves. Moreover, the $70 \%$ hydro-methanolic extract of oleander leaves were demonstrated to possess anti-inflammatory activities by modulation of Th1/Th2 cytokine levels accompanied by inhibition of $\mathrm{NO}, \mathrm{COX}$ and $\mathrm{PGE}_{2}$ levels in concanavalin $\mathrm{A}$ activated murine splenic lymphocytes $[15,16]$. In the present study, $\mathrm{CCl}_{4}$ toxicity resulted significant $(p<$ 0.001 ) increase in TNF- $\alpha$ and NO levels, which were subsequently lowered by the oleander extracts. This exhibited potent anti-inflammatory activities of oleander 
extracts through suppression of pro-inflammatory mediators of chronic hepatotoxicity.

The hepatoprotective potentiality of oleander extracts were further established through detailed histopathological studies. The results clearly demonstrated that deformed hepatic architecture due to $\mathrm{CCL}_{4}$ toxicity was subsequently attenuated by oleander extracts. $\mathrm{CCl}_{4}$ toxicity initiated tremendous hepatocellular degeneration as evident by scattered hepatocellular necrosis and in some cases with central haemorrhagic necrosis. Deformed nucleus containing overlapping hepatocytes with irregular cellular margins were characteristics of $\mathrm{CCl}_{4}$ group which highly contrasted the prominent nucleus containing healthy hepatocytes with conspicuous cellular boundaries in the control. Loss of cellular integrity in the $\mathrm{CCl}_{4}$ group were visible in terms of disorganized arrangement of the hepatocytes. Interestingly, liver samples of the $\mathrm{CCl}_{4}$ group exhibited an extensive, yet typical signs of inflammation by means of infiltration of leukocytes from the portal regions extended towards the hepatocyte rich central zones, which were comparatively less in the silymarin and extract treated groups. Extensive fatty infiltration throughout the $\mathrm{CCl}_{4}$ group liver samples signified initiation of macrovascular steatosis and adipose degeneration that were less in the NOSE and NORE groups. Moreover, the deformity of the hepatic nodules associated vascular congestions with occasional bile duct proliferations were also lowered in the silymarin and extract treated groups. Overall, the deformed hepatocellular architecture of the $\mathrm{CCl}_{4}$ group were significantly normalized by oleander extracts.

NOSE and NORE were further analysed using FTIR and GC-MS method to reveal the phytochemical constituents responsible for the potent hepatoprotective potentiality. Different functional groups were identified through FTIR analysis, which correlating with the compounds identified in the GC-MS study. Alkanes like tetradecane and hexadecane resulted in $=\mathrm{C}-\mathrm{H}$ bending. The $\mathrm{C}-\mathrm{O}$ stretching of carboxylic moiety resulted due to the presence of linoleic acid, n-hexadecanoic acid, benzoic acid, eicosenoic acid, oleic acid etc. The O-H stretching of the alcohol/phenolic species were supported by the presence of lupeol, amyrin, isoeugenol, vanillin and other phenolic phytochemicals. In GC-MS analysis, both the fractions of the extracts revealed the presence of several bioactive constituents which corroborates a previous report of a preliminary phytochemical analysis of oleander [51]. The $70 \%$ hydro-methanolic extracts of oleander leaf, steam and root possessed high amount of phenolic and flavonoid contents, contributing to its antioxidant and free radical scavenging activities [11]. A detailed account of related bioactivities of individual phytocompounds are enlisted in Additional file 5, which supports the view that the hepatoprotective activity of oleander extract resulted due to additive and synergistic activities of the component phytochemicals.

\section{Conclusion}

The present study demonstrated that oleander stem and root extracts attenuated reactive species mediated liver damage which was evident through significant lowering of lipid peroxidation and elevation of antioxidant enzymatic activities. Normalization of the liver enzymatic and biochemical markers under both in vivo and in vitro liver function tests provided convincing evidence of the hepatoprotective potentialities of the oleander extracts. Histopathological studies provided confirmative visual support towards the improvement of hepatic architecture as well. Therefore, it may be concluded that oleander extracts ameliorated $\mathrm{CCl}_{4}$ induced liver injury primarily through normalization of liver antioxidant enzymes and inhibition of pro-inflammatory signals. The hepatoprotective activities may be attributed to the presence of bioactive constituents in the extracts. The mode of hepatoprotective activity of oleander may thus, be represented as Fig. 7. Our future endeavour will be isolation and characterization of major bioactive species and detailed study of their physiological implications.

\section{Additional files}

\section{Additional file 1: Preparation of $70 \%$ hydro-methanolic extract of} oleander stem and root. (DOCX $153 \mathrm{~kb}$ )

Additional file 2: Summarizes the percentage change of different enzymatic and biochemical parameters in the serum samples and culture medium. (DOCX $16 \mathrm{~kb}$ )

Additional file 3: Fourier transform infrared spectroscopy peak values of NOSE and NORE corresponding to Fig. 5. (DOCX $17 \mathrm{~kb}$ )

Additional file 4: Chemical fingerprint of dichloromethane fraction of NOSE corresponding to Fig. 6a. Chemical fingerprint of n-hexane fraction of NOSE corresponding to Fig. 6b. Chemical fingerprint of dichloromethane fraction of NORE corresponding to Fig. $6 c$. Chemical fingerprint of $n$-hexane fraction of NORE corresponding to Fig. 6 d. (DOCX 29 kb)

Additional file 5: Bioactivities of identified compounds. $\boldsymbol{\Delta}$ means increase; $\boldsymbol{\nabla}$ means decrease; means no change. (DOCX 33 kb)

\begin{abstract}
Abbreviations
ACP, acid phosphatase; ALP, alkaline phosphatase; ALT, alanine transaminase; AST, aspartate transaminase; $\mathrm{CCl}_{4}$, carbon tetrachloride; DW, dry weight; FTIR, Fourier Transform Infrared; GC-MS, Gas chromatography-mass spectrometry; GGT, gamma-glutamyl transferase; LDH, lactate dehydrogenase; MDA, malondialdehyde; MTT, 3-(4,5-dimethylthiazol-2-yl)-2,5-diphenyltetrazolium bromide; NO, nitric oxide; NORE, Nerium oleander root extract; NOSE, Nerium oleander stem extract; SDS, sodium dodecyl sulphate; TBARS, thiobarbituric acid reactive substances; TNF-a, tumor necrosis factor-a.
\end{abstract}

\section{Acknowledgements}

The authors are grateful to Mr. Bijoy Mahanta for his assistance in animal maintenance.

Funding

The present study was not supported by any external funding agencies. 


\section{Availability of data and materials}

The supporting materials can be obtained upon request via email to the corresponsing author.

\section{Authors' contributions}

PD performed the in vitro and in vivo experiments, statistical analysis and drafted the manuscript. SD assisted in the in vivo experiments and performed the histopathological study. ABR performed the GC-MS analysis. MPS supervised the phytochemical analysis, analysed the GC-MS data and drafted the phytochemical part of the manuscript. TKC designed, supervised and coordinated the study and drafted the manuscript. All authors have read and approved the final version of the manuscript.

\section{Competing interests}

The authors declare that they have no competing interests.

\section{Consent for publication}

This section is not applicable for the study.

\section{Ethics approval and consent to participate}

All the experiments were approved by the ethical committee, University of North Bengal (No. 840/ac/04/CPCSEA) and conducted in accordance with the legislation for the protection of animals used for scientific purposes. The study does not include human subjects.

\section{Author details}

'Cellular Immunology Laboratory, Department of Zoology, Life Science Building, University of North Bengal, PO: Raja Rammohunpur, Siliguri 734013, West Bengal, India. ${ }^{2}$ Chemical Signal and Lipidomics Laboratory, Department of Botany, University of Calcutta, Kolkata 700019, India.

\section{Received: 28 January 2016 Accepted: 5 August 2016} Published online: 11 August 2016

\section{References}

1. Dey P, Saha MR, Sen A. Hepatotoxicity and the present herbal hepatoprotective scenario. Int J Green Pharm. 2013:7:265-73.

2. Subramoniam A, Pushpangadan P. Development of phytomedicines for liver diseases. Indian J Pharm. 1999:31:166-75.

3. World Health Organization. Guidelines for the appropriate use of herbal medicines: the role of herbal medicines. 1998. http://apps.who.int/ medicinedocs/en/d/Jh2945e/. Accessed 10 Mar 2014.

4. Kaplowitz N. Idiosyncratic drug hepatotoxicity. Nature. 2005;4:489-99.

5. Jones AL. Anatomy of the normal liver. In: Zakin D, Boyer TD, editors Hepatology: a textbook of liver disease. Philadelphia: WB Saunders; 1996 p. 3-32.

6. Dey P, Saha MR, Sen A. An overview on drug-induced hepatotoxicity. Asian J Pharm Clin Res. 2013:6:1-4.

7. Sturgill MG, Lambert GH. Xenobiotic-induced hepatotoxicity: mechanisms of liver injury and methods of monitoring hepatic function. Clin Chem. 1997; 43:1512-26.

8. Weber LW, Boll M, Stampfl A. Hepatotoxicity and mechanism of action of haloalkanes: carbon tetrachloride as a toxicological model. Crit Rev Toxicol. 2003;33:105-36.

9. Recknagel RO. Carbon tetrachloride hepatotoxicity. Pharmacol Rev. 1967;19: 145-208.

10. Belkin S. Biodegradation of haloalkanes. Biodegradation. 1992:922:299-313.

11. Dey P, Chaudhuri D, Chaudhuri TK, Mandal N. Comparative assessment of the antioxidant activity and free radical scavenging potential of different parts of Nerium indicum. Int J Phytomed. 2012;4:54-69.

12. Batts KP. Iron overload syndromes and the liver. Mod Pathol. 2007:20:S31-9.

13. Ghate NB, Chaudhuri D, Panja S, Mandal N. Nerium indicum leaf alleviates iron-induced oxidative stress and hepatic injury in mice. Pharm Biol. 2015; 53:1066-74.

14. Dey P, Dutta S, Sarkar MP, Chaudhuri TK. Assessment of hepatoprotective potential of $N$. indicum leaf on haloalkane xenobiotic induced hepatic injury in Swiss albino mice. Chem Biol Interact. 2015;235:37-46.

15. Dey P, Chaudhuri TK. Immunomodulatory activity of Nerium indicum through inhibition of nitric oxide and cyclooxygenase activity and modulation of $\mathrm{TH} 1 / \mathrm{TH} 2$ cytokine balance in murine splenic lymphocytes. Cytotechnology. 2015. (ahead of print).
16. Dey P, Chaudhuri TK. Anti-inflammatory activity of Nerium indicum by inhibition of prostaglandin E2 in murine splenic lymphocytes. Indian $J$ Pharm. 2015:47:447-50.

17. Dey P, Chaudhuri TK. Pharmacological aspects of Nerium indicum Mill: a comprehensive review. Pharmacogn Rev. 2014;8:156-62.

18. OECDiLibrary. OECD Guidelines for the testing of chemicals, Section 4: Health effects; 2002. doi:10.1787/9789264071001-en. ISBN: 9789264071001 (PDF).

19. Sadasivam S, Manickam A. Biochemical methods. India: Mew Age International; 2008

20. Luck H. Catalase. In: Bergmeyer HW, editor. Methods of enzymatic analysis. New York: Accademic press; 1963. p. 885

21. Freshney R. Culture of animal cells: a manual of basic technique. USA: John Wiley \& Sons, Inc; 2005.

22. Mishra S, Sahoo S, Rout KK, Nayak SK, Mishra SK, Panda PK. Hepatoprotective effect of Barringtonia acutangula Linn. leaves on carbon tetrachloride-induced acute liver damage in rats. Indian J Nat Prod Resour. 2011:2:515-9.

23. Hibbs JB, Taintor RR, Vavrin Z, Rachlin EM. Nitric oxide: a cytotoxic activated macrophage effector molecule. Biochem Biophys Res Commun. 1988;157:87-94.

24. Silverstein RM, Bassler GC, Morrill TC. Spectrometric identification of organic compounds. New York: John Wiley and Sons; 2007.

25. Ruprah M, Mant TGK, Flanagan RJ. Acute carbon tetrachloride poisoning in 19 patients: implications for diagnosis and treatment. Lancet. 1985;1:1027-9.

26. Stewart RD, Dodd HC. Absorption of carbon tetrachloride, trichloroethylene, tetrachloroethylene, methylene chloride and I, I, I-trichloroethane through the human skin. Am Ind Hyg Assoc J. 1964;25:439-46.

27. New PS, Lubash GD, Scherr L, Rubin A. Acute renal failure associated with carbon tetrachloride intoxication. J Am Med Assoc. 1962;181:903-6.

28. U.S. Environmental Protection Agency. Toxicological review of carbon tetrachloride; 2010. http://www.epa.gov/iris/toxreviews/0020tr.pdf. Accessed: 12/06/2015

29. Recknagel RO, Glende EA, Dolak JA, Waller RL. Mechanisms of carbon tetrachloride toxicity. Pharmacol Ther. 1989;43:139-54.

30. Gayathri V, Ananthi S, Chandronitha C, Sangeetha MK, Vasanthi HR. Hypolipidemic potential of flowers of Nerium oleander in high fat diet-fed Sprague Dawley rats. Nat Prod Res. 2010:25:1110-4.

31. Amacher DE. A toxicologist's guide to biomarkers of hepatic response. Hum Exp Toxicol. 2002:21:253-62.

32. Zimmerman HJ. Drug-induced hepatic disease. In: Plaa GL, Hewitt WR, editors. Toxicology of the liver. Washington: Taylor and Francis; 1998. p. 3-60.

33. Zimmerman HJ. Drug-induced liver disease. Clin Liver Dis. 2000;4:73-96.

34. Gayathri V, Ananthi S, Chandronitha C, Ramakrishnan G, Lakshmisundaram R, Vasanthi HR. Cardioprotective effect of Nerium oleander flower against isoproterenol-induced myocardial oxidative stress in experimental rats. J Cardiovasc Pharmacol Ther. 2011;16:96-104.

35. Dey P, Saha MR, Chowdhuri SR, Sen A, Sarkar MP, Haldar B, et al. Assessment of anti-diabetic activity of an ethnopharmacological plant Nerium oleander through alloxan induced diabetes in mice. J Ethnopharmacol. 2014;161:128-37.

36. Zhao ZS, O'Brien PJ. The prevention of $\mathrm{CCl}_{4}$-induced liver necrosis in mice by naturally occurring methylenedioxybenzenes. Toxicol Appl Pharmacol. 1996;140:411-21.

37. Slater TF, Cheeseman KH, Ingold KU. Carbon tetrachloride toxicity as a model for studying free-radical mediated liver injury. Philos Trans R Soc Lond B Biol Sci. 1986;311:633-45.

38. Hashimoto S, Glende Jr EA, Recknagel RO. Hepatic lipid peroxidation in acute fatal human carbon tetrachloride poisoning. N Engl J Med. 1968;279:1082-5.

39. Basu S. Carbon tetrachloride-induced lipid peroxidation: eicosanoid formation and their regulation by antioxidant nutrients. Toxicology. 2003;189:113-27.

40. Tsai CF, Hsu YW, Chen WK, Chang WH, Yen CC, Ho YC, et al. Hepatoprotective effect of electrolyzed reduced water against carbon tetrachloride-induced liver damage in mice. Food Chem Toxicol. 2009:27:2031-6.

41. Stohs SJ, Bagchi D. Oxidative mechanisms in the toxicity of metal-ions. Free Radical Bio Med. 1995:18:321-36.

42. Flora SJ, Mittal M, Mehta A. Heavy metal induced oxidative stress and its possible reversal by chelation therapy. Indian J Med Res. 2008;128:501-23.

43. Valko M, Izakovic M, Mazur M, Rhodes CJ, Telser J. Role of oxygen radicals in DNA damage and cancer incidence. Mol Cell Biochem. 2004;266:37-56.

44. Singhal KG, Gupta GD. Hepatoprotective and antioxidant activity of methanolic extract of flowers of Nerium oleander against $\mathrm{CCl}_{4}$-induced liver injury in rats. Asian Pac J Trop Med. 2012;5:677-85. 
45. Morio LA, Chiu H, Sprowles KA, Zhou P, Heck DE, Gordon MK, et al. Distinct roles of tumor necrosis factor-alpha and nitric oxide in acute liver injury induced by carbon tetrachloride in mice. Toxicol Appl Pharmacol. 2001;172:44-51.

46. Afford C, Lalor F. Cell and molecular mechanisms in the development of chronic liver inflammation in liver diseases. In: Ali S, Friedman SL, Mann DA, editors. Liver diseases biochemical mechanisms and new therapeutic insights. USA: Science publishers; 2006. p. 147-63.

47. Gabele E, Froh M, Arteel GE, Uesugi T, Hellerbrand C, Scholmerich J. TNFalpha is required for cholestasis-induced liver fibrosis in the mouse. Biochem Biophys Res Commun. 2009;378:348-53.

48. Al-Shabanah OA, Alam K, Nagi MN, Al-Rikabi AC, Al-Bekairi AM. Protective effect of aminoguanidine, a nitric oxide synthase inhibitor, against carbon tetrachloride induced hepatotoxicity in mice. Life Sci. 2000;66:265-70.

49. Khare CP. Indian medicinal plants. New York: Springer; 2007.

50. Erdemoglu N, Kupeli E, Yesilada E. Anti-inflammatory and antinociceptive activity assessment of plants used as remedy in Turkish folk medicine. J Ethnopharmacol. 2003:89:123-9.

51. Dey P, Roy S, Chaudhuri TK. A quantitative assessment of bioactive phytochemicals of Nerium indicum: an ethnopharmacological herb. Int J Res Pharm Sci. 2012;3:579-87.

Submit your next manuscript to BioMed Central and we will help you at every step:

- We accept pre-submission inquiries

- Our selector tool helps you to find the most relevant journal

- We provide round the clock customer support

- Convenient online submission

- Thorough peer review

- Inclusion in PubMed and all major indexing services

- Maximum visibility for your research

Submit your manuscript at www.biomedcentral.com/submit
Biomed Central 